\title{
A Multi-Modality Surgical Management in Laryngeal Stenosis
}

\author{
Ashfaque Ansari, ${ }^{1}$ Annju Thomas ${ }^{1}$
}

\begin{abstract}
Introduction
Postintubation laryngo-tracheal stenosis requires a precise diagnosis and an experienced operator in both endoscopic and surgical treatment. This report presents surgically treated cases of laryngo-tracheal stenosis secondary to long-term intubation/ tracheostomy with review of the literature.

Case Reports

In this retrospective study, we present 5 cases (23-year-old male, 13 year old male, 22 year old male, 19 year old male and 33 year old female) of post-intubation/tracheostomy laryngo-tracheal stenosis (glottic/subglottic) stenosis in the year 2016 to 2017. Each patient was managed differently. A patient with history of multiple subglottic stenosis dilations and stenting underwent open surgical subglottic stenosis resection and anastomosis, LASER assisted resection of stenosis with stenting was done in a patient with history of dilation, LASER assisted resection and dilation followed by Mitomycin C application was done in another patient with history of poisoning, plain endoscopic dilation was done in one patient with history of head injury and Kashima's Cordotomy with release of interarytenoid adhesion by LASER was done in one patient.

Conclusion

Resection of stenotic segment by open surgical anastomosis and laser assisted resection is a safe option for the treatment of subglottic stenosis following intubation without the need for repeated dilation. Endoscopic dilation can be reserved for unfit patients.
\end{abstract}

$\underline{\text { ABSTRACT }}$

$\underline{\text { Keywords }}$

Laryngostenosis; Tracheal Stenosis; Intubation; Endoscopy; Anastomosis, Surgical; Cordotomy

$\mathrm{L}$ aryngo-tracheal stenosis is a congenital or acquired narrowing of the airway that may affect the supraglottis, glottis, and/or subglottis. It has several grades. Incidence of laryngo-tracheal stenosis following intubation has been reported upto $21 \%{ }^{1}$ However, only a few (1-2\%) of these patients present with the symptoms. Resection and anastomosis has been established as the definitive treatment of stenosis more than one $\mathrm{cm}$ in length. ${ }^{2}$ The current study aims to present cases of laryngo-tracheal stenosis managed by different methods at our hospital.

\section{Case Reports}

\section{CASE 1:}

A 23 years old male came to our OPD with complains of change of voice and noisy breathing. Examination revealed the young man had inspiratory stridor and hoarseness of voice with portex tracheostomy tube no 8 in situ. History revealed that he was admittedpreviously for organophosphorus poisoning 3 years back, during which he was intubated for 15 days. After extubation, he was kept in the ward for 5 days after which he was discharged. Patient developed dyspnoea 1 month after discharge from primary hospital, patient was admitted and taken up for emergency tracheostomy. Following which a clinical diagnosis of tracheal stenosis was made.

CT Neck revealed subglottic stenosis proximal to tracheostomy stoma involving length of $2 \mathrm{~cm}$ and transverse diameter of $6 \mathrm{~mm}$.

After which patient underwent 6 check bronchoscopies

1 - Department of ENT, MGM Medical College and Hospital,Aurangabad, Maharashtra, India

Corresponding author:

Dr Annju Thomas

email: tannju@yahoo.in 

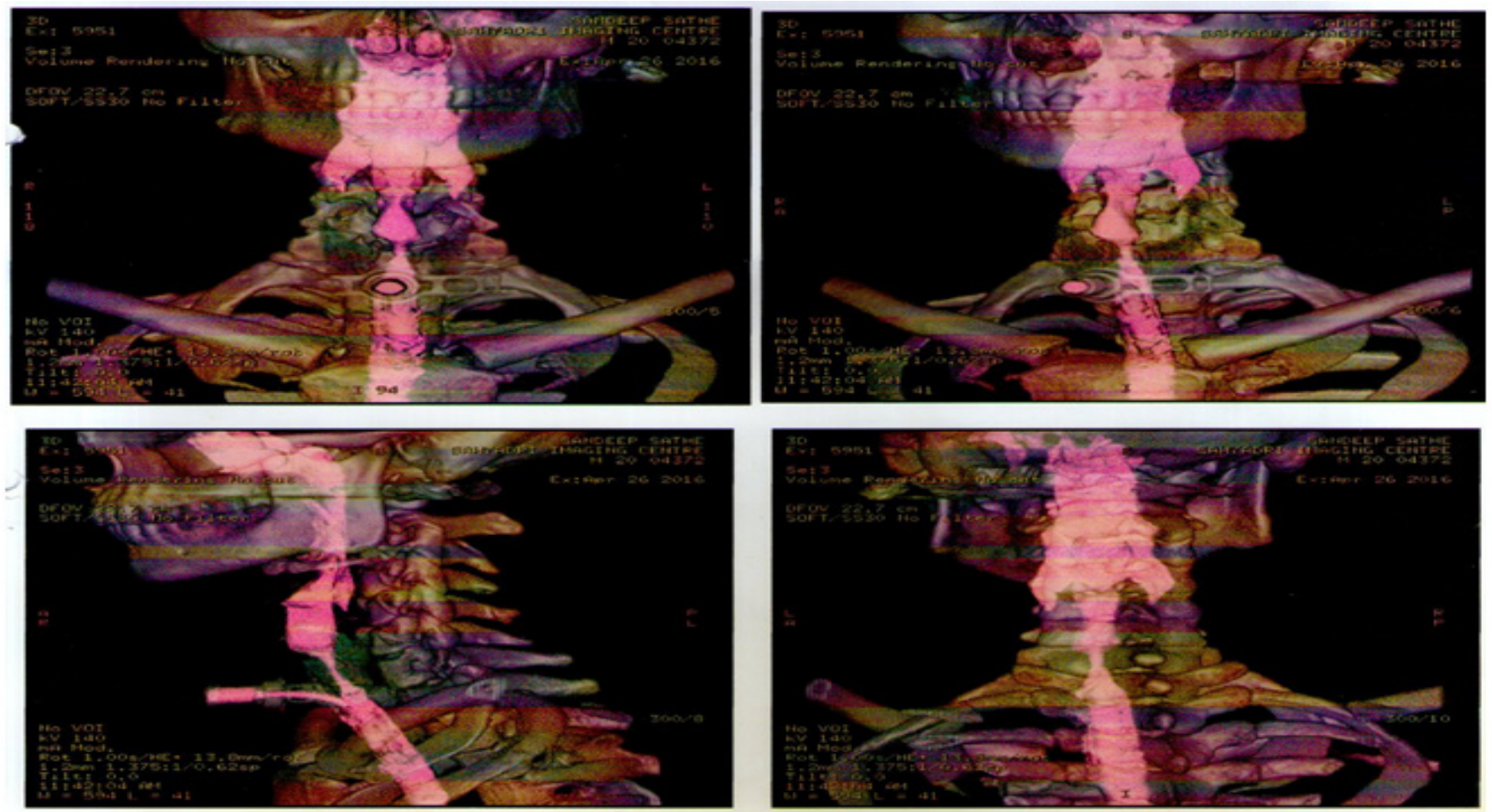

Fig. 1. 3D CT neck showing stenotic portion
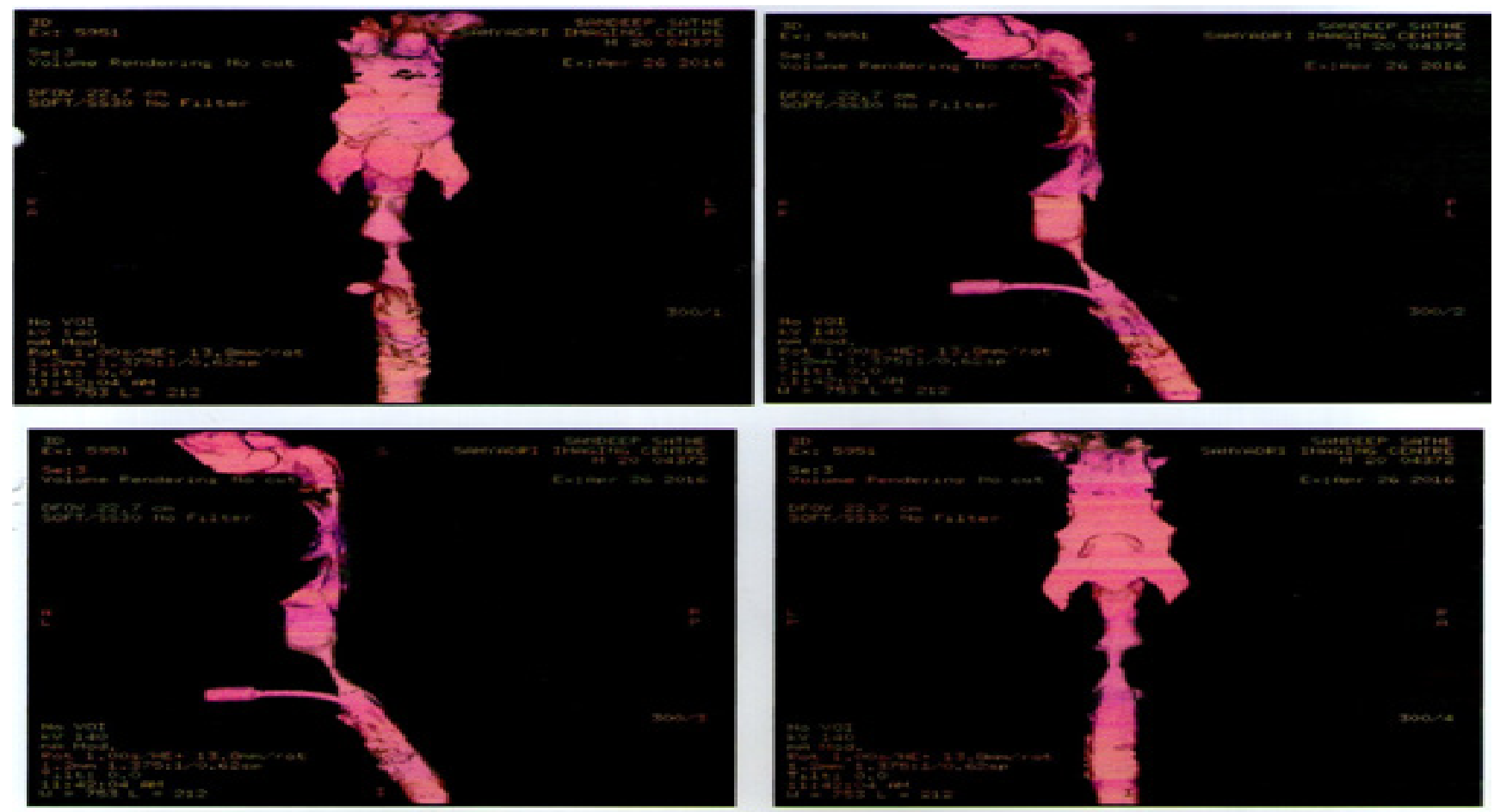

Fig. 2. 3D CT neck showing stenotic portion 


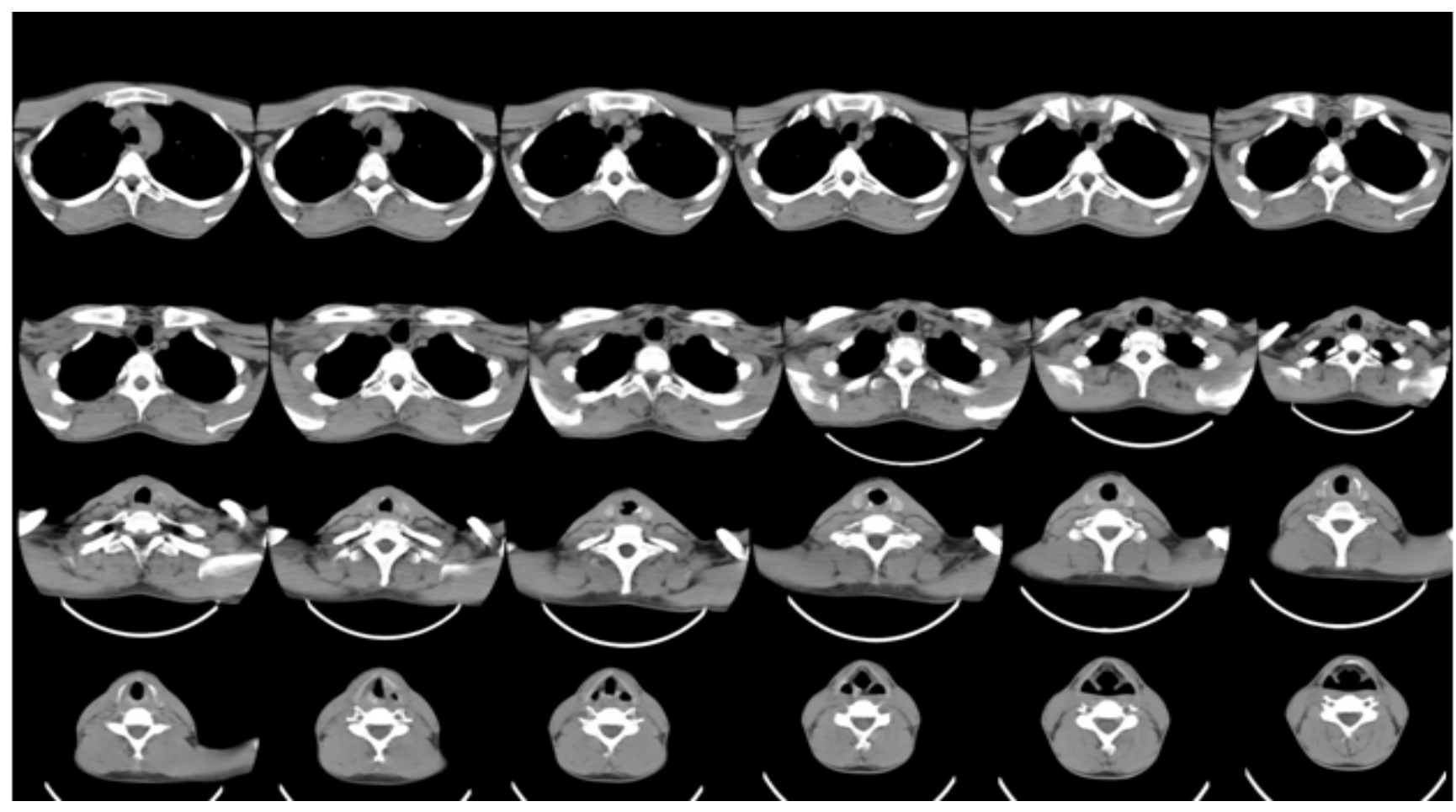

Fig. 3. CT Neck 6 month post operatively

and 3 dilations and followed by stenting of the subglottic stenosis in at the previous hospital, which did not relieve him of his complains. He underwent a check bronchoscopy with dilation of the tracheal stenosis at our hospitall year later.

Patient returned back to our ENT OPD 1 year after the dilationwith complains of hoarseness of voice and stridor. 3 DCT neck (Fig. 1 \& 2) revealed subglottic stenosis over approx. length $11 \mathrm{~mm}$, noted at level of cricoid cartilage. Transverse diameter $5.5 \mathrm{~mm}$ and AP diameter measures $5.1 \mathrm{~mm}$. There was grade III (90\%) stenosis over the third tracheal ring with narrowing extending proximally up to second ring. CT scan showed a stenotic segment of $2.5 \mathrm{~cm}$. The patient and his relatives were explained about the condition and the procedure to be performed. They agreed for a reconstructive surgery and a tracheal resection and anastomosis was planned.

Patient underwent surgery, Apron neck incision was given. Flaps elevated superiorly till the hyoid bone and inferiorly till the clavicle. Strap muscles separated and thyroid gland dissected. Trachea visualized and stenotic portion of the trachea was resected and end to end anastomosis done with 3/0 monofilament polypropylene suture material a vacuum drain was kept insitu. A mento-sternal suture with neck in flexion to restrict neck movement was placed with $1 / 0$ polypropylene. Post operatively patient was kept in ICU with nasal intubation. Nasal intubation and drain were removed on the 5th postoperative day. Patient was shifted out of ICU on the 8th post-operative day made uneventful recovery and was discharged on 14th postoperative day. During follow up after one month, patient was asymptomatic with normal breathing and voice.

CT Neck 6 month post operatively suggested of no evidence of stenosis. (Fig. 3) Tracheal lumen and tracheal bifurcation were normal and on $70^{\circ}$. Rigid fibreoptic laryngoscopy, vocal cord mobility was normal.

\section{CASE 2:}

A 13 year old male was referred to our OPD with complains of dyspnea, noisy breathing. Examination revealed patient had inspiratory stridor with metallic tracheostomy tube insitu. On indirect laryngoscopy bilateral vocal cords were mobile. History revealed that 


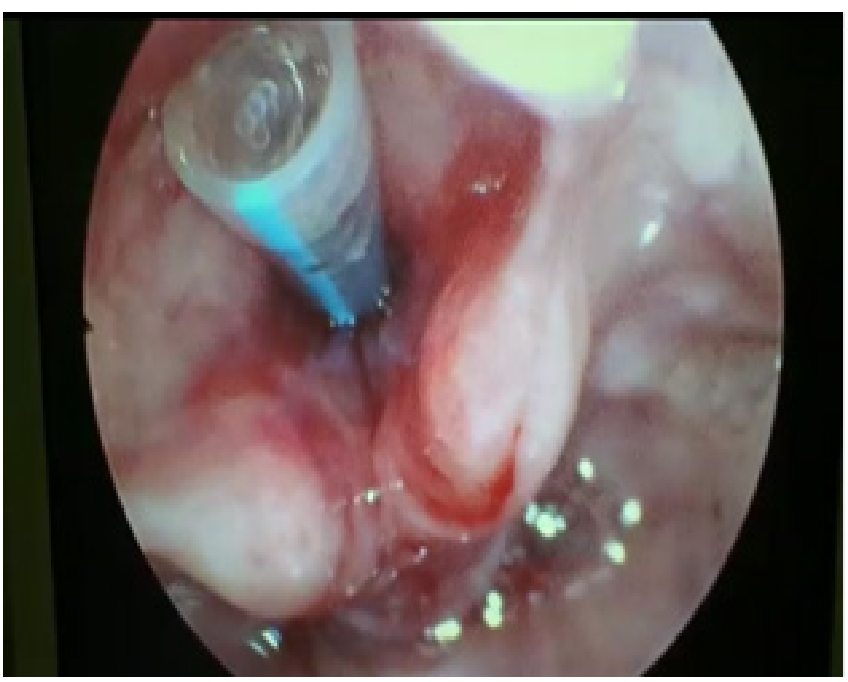

Fig. 4. Endotracheal tube number 4 inserted after LASER assisted release of stenosis

patient was admitted in view of neuroparalysis secondary to snake bite 2 months back. Patient was ventilated through an endotracheal tube for 10 days after which underwent a tracheostomy. Patient was shifted to ward on the 23rd day after admission. Patient was discharged with a metallic tube insitu. Post discharge patient complained of noisy breathing. Patient underwent flexible bronchoscopy which revealed subglottic stenosis, bilateral fixed vocal cords due to thickening and fibrosis. Patient underwent balloon dilation which did not relieve his complaints Patient was referred to our hospital for further management. The patient's relatives were explained about the condition and the procedure to be performed. They agreed for the surgery and LASER assistedtransglottic stenosis excision was planned.

Patient underwent the surgery under general anaesthesia, flexible bronchoscopy was done. Flappy epiglottis visualized, glottis stenosis with interarytenoid adhesion seen. Subglottic soft stenosis (Cotton Myer's grade 4) visualized. Rigid bronchoscopy was done and stenotic segment length was assessed. Bogdasarian grade 4 post glottic stenosis was noted and partly released with $\mathrm{CO} 2$ laser. Bougie was used for dilation of the subglottic stenosis. $\mathrm{CO} 2$ laser was used to release the stenotic bands of the subglottic stenosis. Endotracheal tube number 4 was inserted through the tracheostomy(Fig. $4 \& 5$ ) site upwards in a retrograde

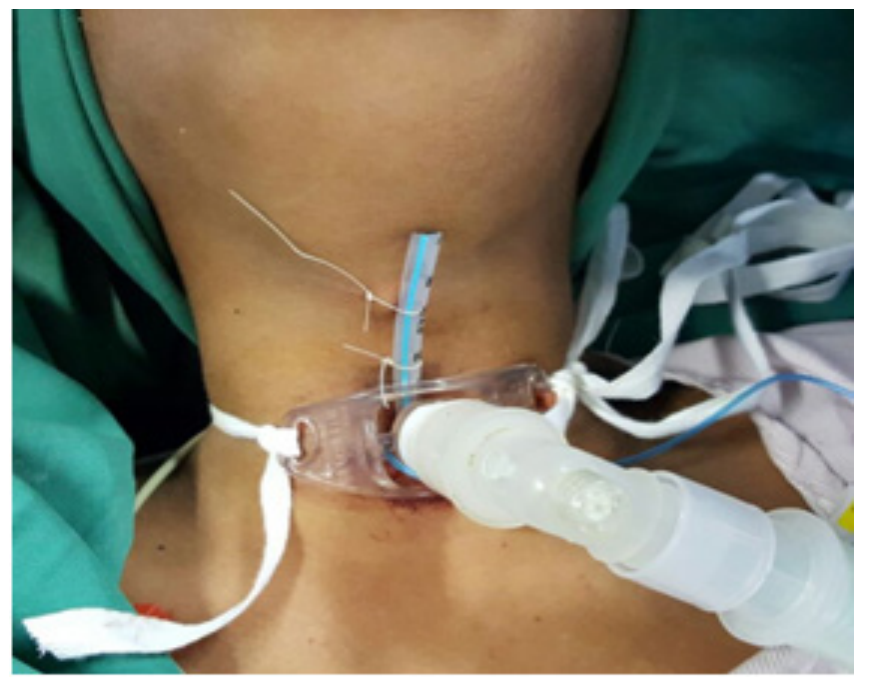

Fig. 5. Endotracheal tube number 4 inserted after LASER assisted release of stenosis

fashion through the stenosis to maintain patency.

Post operatively patient was kept in ICU. Patient was shifted out of ICU on the 3rd post-operative day. Patient made uneventful recovery with no complains of dyspnea and noisy breathing. Patient was discharged on 20th postoperative day after Montgomery T-tube insertion. Post operatively after 6 month the Montgomery T- tube was removed. One month after $\mathrm{T}$ tube removal there was no evidence of stridor and no recurrence of stenosis.

\section{CASE 3:}

A 22 year old male our OPD with complains of dyspnea on lying down, hoarseness of voice. Examination revealed patient had orthopnea, stridor. On laryngoscopy bilateral vocal cords were fixed with inter-arytenoid adhesion and with subglottic stenosis. History revealed that patient had history of hospitalization in view of OP poisoning. Patient was intubated for 2 weeks. Patient was shifted to ward post extubation on the 3 rd week after admission. Patient was discharged. Post discharge patient complained of hoarseness of voice and dyspnoea.

Patient came to our OPD where on indirect laryngoscopy it was revealed patient has bilateral abductor cord palsy with interarytenoid adhesion and on flexible bronchoscopy there was astenosis 

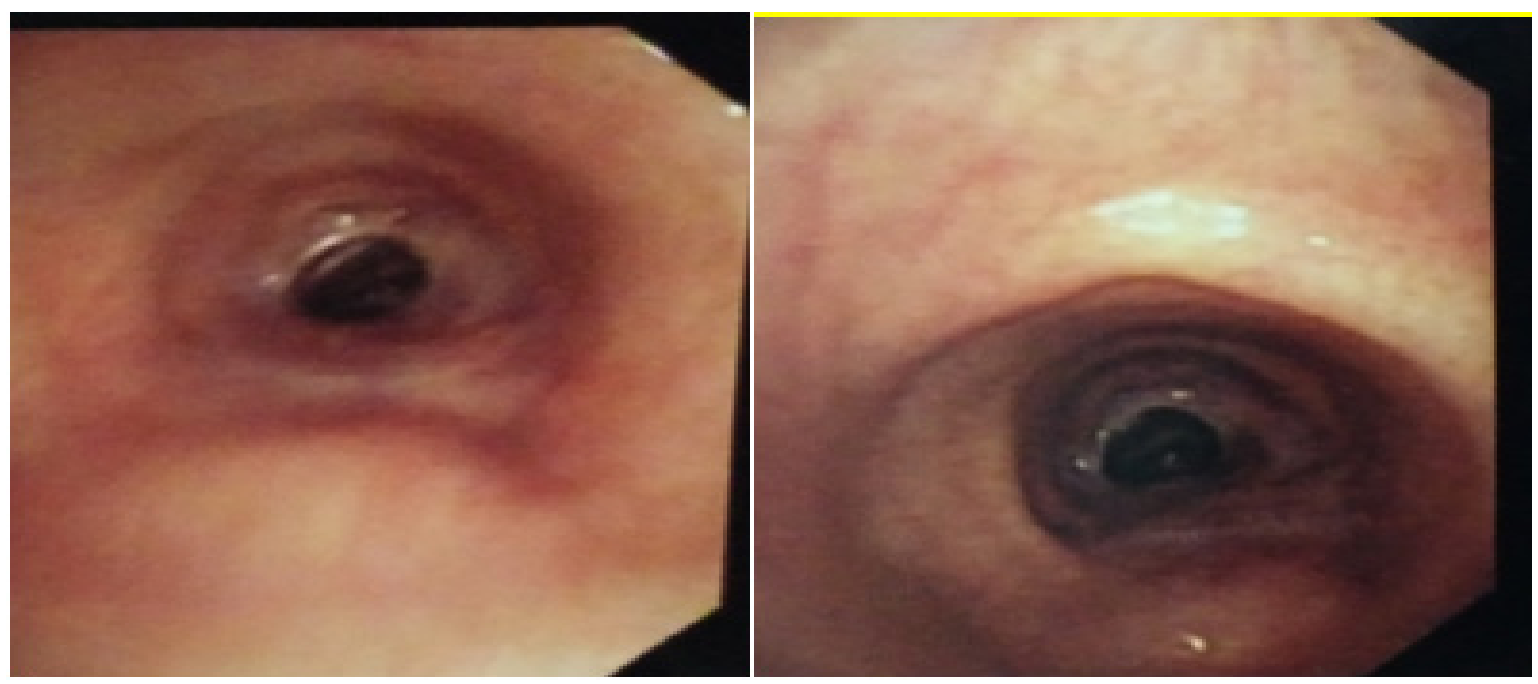

Fig. 6. Stenosis seen $4 \mathrm{~cm}$ below glottis

seen $4 \mathrm{~cm}$ below the glottis, which was grade II soft stenosis. (Fig. 6) The patient's relatives were explained about the condition of the patient and the procedure to be performed. They agreed for the surgery and microlaryngoscopic Kashima's cordotomy by LASER was planned with dilation of subglottic stenosis.

Patient underwent surgery under general anaesthesia, after intubation, the scope was introduced. Bilateral vocal cords were visualized, posterior commissure was visualized. Right side cordotomy was done using LASER. Followed by dilation of stenotic portion using rigid bronchoscope. Patient was shifted to ICU post operatively and was shifted out on 3rd post-operative day.

Patient made an uneventful recovery and was discharged from ENT ward on 9th post-operative day. Six months postoperatively on endoscopic examination there was no evidence of glottis or subglottic stenosis or stridor.

\section{CASE 4:}

A 19 year old boy was brought to our OPD with complains of dyspnea. Examination revealed patient had stridor and a PVC tracheostomy tube insitu. On indirect laryngoscopy bilateral vocal cords were mobile. History revealed that patient was admitted in another hospital 1 month prior to visit at our hospital in view of head injury. Patient had undergone craniotomy for the same with tracheostomy. Patient was discharged after an uneventful recovery after decannulating him. Patient developed dyspnoea 15 days post discharge. Patient underwent tracheostomy once again. Patient was discharged with PVC tracheostomy tube no 8. Patient came to our OPD in view of dyspnea after which a CT neck was performed suggestive of tracheostomy insitu $3 \mathrm{~cm}$ from the carina with tracheal stenosis at the level of tracheostomy tube. The patient's relatives were explained about the condition of the patient and the procedure to be performed. They agreed for the surgery and flexible bronchoscopy with dilation of subglottic stenosis was planned.

The surgery was done under local anaesthesia. Rigid bronchoscope was introducedand 8 no PVC tracheostomy tube was removed. Tracheal stenosis visualized at level of tracheostoma.(Fig. 7) Tracheal stenosis was mild and granulation tissue was present. Dilation was done using balloon dilator and tracheostomy tube no 7 was inserted. Patient was shifted to ward post operatively and was discharged with metallic tracheostomy tube on the 3rd postoperative day.Patient followed up on 15th postoperative day and tracheostomy decannulation was done after check bronchoscopy. There was no evidence of subglottic stenosis. 

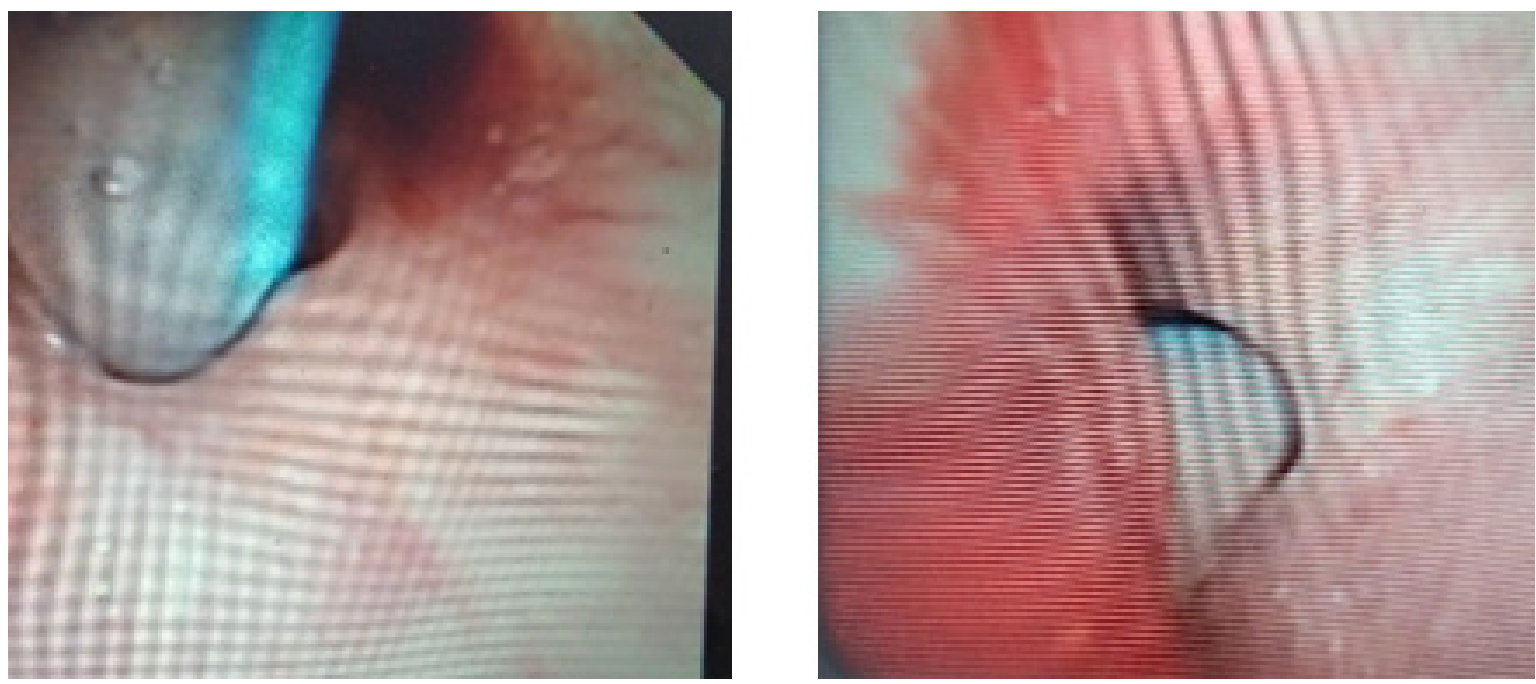

Fig. 7. Tracheal stenosis at level of tracheostoma

\section{CASE 5:}

A 33 year old female was referred to our OPD with complaints of hoarseness of voice and dyspnea on exertion. Examination revealed patient had stridor. On indirect laryngoscopy bilateral vocal cords mobile. History revealed that patient was admitted in view of clozapine poisoning and was kept intubated for 10 days. Post extubation patient made an uneventful recovery and was discharged on the 5thday after shifting to ward. She subsequently developedhoarseness and dyspnea on exertion. CT scan revealed narrowing of trachea for

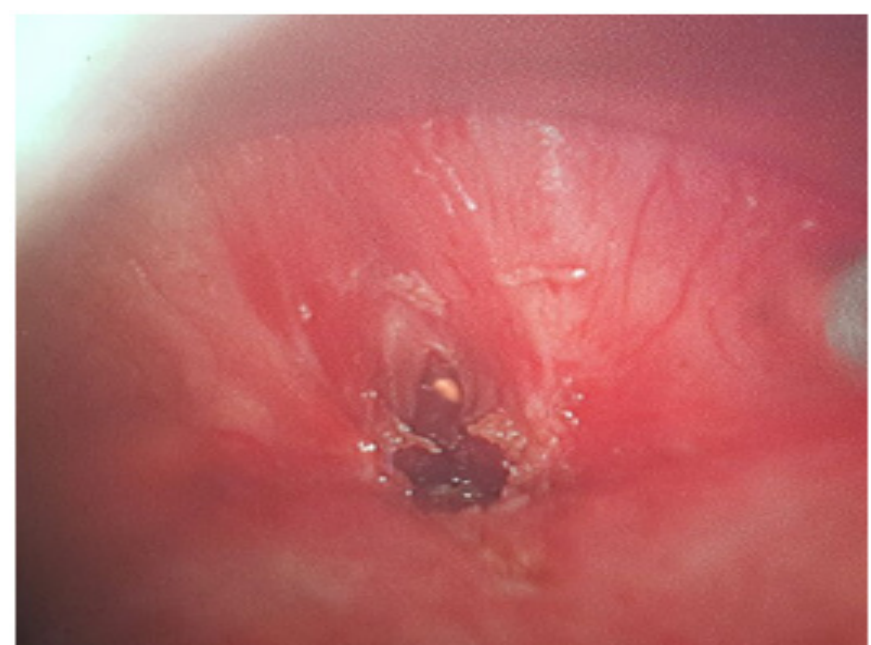

Fig. 8. LASER excision of stenosis an approximate length $2 \mathrm{~cm}$ from $\mathrm{C} 7-\mathrm{T} 1$ to $\mathrm{T} 1-\mathrm{T} 2$. The patient's relatives were explained about the condition of the patient and the procedure to be performed.

They agreed for the surgery and excision of stenosis done by Holmium LASER (Fig. 8) with balloon dilation followed by Mitomycin $\mathrm{C}$ application. Patient was shifted to ICU post operatively and was shifted out on 2nd postoperative day. Patient made an uneventful recovery and was discharged from ENT ward on 5thpost operative day.Post operative ${ }^{6}$ month check bronchoscopy revealed no evidence of subglottic stenosis.

\section{Discussion}

Endotracheal intubation is a known cause of glottic/ subglottic stenosis. The other important cause being complication of tracheostomy and surgical/external trauma.

Post intubation stenosis is a clinical problem caused by regional ischaemic pressure necrosis of the airway. ${ }^{3}$ Stenosis can occur anywhere from the level of the endotracheal tube tip till the glottic and subglottic area. The most common sites of stenosis are where the endotracheal cuff has been in contact with the tracheal wall and at the tracheal stoma site following a tracheostomy. ${ }^{4}$ As a result, stenosis occurs most commonly following the two types of airway intubation:- endotracheal intubation and tracheostomy. ${ }^{5}$ 
Causative factor of stenosis is the pressure exerted by the cuff on the tracheal mucosa. At a cuff pressure of $>30 \mathrm{mmHg}$, there is an increase in mucosal capillary perfusion pressure, which leads to mucosal ischemia and consequent inflammation of the tracheal cartilages. These pathological changes may eventually lead to fibrosis of circumferential lesions, resulting in progressive tracheal stenosis. ${ }^{6}$ Ischemic injury can occur even within minutes after insufflation of the cuff, and subsequent fibrotic changes within the following 3-6 weeks. Although the use of large-volume, low-pressure cuffs markedly reduces the occurrence of cuff injury, glottic stenosis continues to occur at a high frequency, with the incidence of post-intubation tracheal stenosis in intensive care units being 6-21\%, although only $1-2$ $\%$ of patients are symptomatic or have severe stenosis. ${ }^{7}$

The diagnosis of laryngo-tracheal stenosis is often missed, and the related symptoms are generally evident only when stenosis of $30 \%$ of the original diameter of the trachea has occurred. Sometimes, the diagnosis may be delayed for as long as three months after the intubation. ${ }^{8}$ Several risk factors of post-intubation stenosis have been recognized thus far, including the size of the endotracheal tube relative to the tracheal lumen, frequent replacement of the endotracheal tube, traumatic intubation, concurrent infection, blood pressure during the intubation period, female gender, estrogen effect, steroid administration, obesity, smoking history, etc. ${ }^{9,10}$

Intubation needed during treatment is the most likely cause of stenosis in the three cases. Development of stenosis following intubation has been reported to occur even with two days of intubation. ${ }^{11}$ A period up to two weeks in adults and even longer in children is generally consider safe.

In the above 5 cases patients were asymptomatic after discharge from their primary care and started showing symptoms of stenosis within 1 month.

The factors that are related to development of stenosis with shorter duration of intubations are large size of the tube, high pressure in cuff, not deflating cuff periodically, struggling or restless patient, traumatic intubation, multiple intubation, infection around the cuff site. ${ }^{11-13}$ All these factors may play a role in development of stenosis.

The assessment of the degree of stenosis is an important step for each patient. Although several grading systems have been proposed, the universally accepted grading of subglottic stenosis was devised by Myer et al in 1994.Grade 1:<50\% obstruction; Grade 2: $51-70 \%$ obstruction; Grade 3: $71-99 \%$ obstruction; Grade 4: no detectable lumen. ${ }^{14}$

Galluccio et al proposed classifying subglottic stenosis as either simple or complex..$^{15}$ They defined simple stenosis as lesions $<1 \mathrm{~cm}$ in length with no associated tracheomalacia or loss of cartilaginous support. Complex lesions were $>1 \mathrm{~cm}$ and had the greatest benefit from surgical intervention. This is significant for our study as our patients had complex lesions.

Complications of open surgical end to end anastomosis include restenosis, dehiscence, granulation, dysphagia and RLN damage.

Granulation tissue formation occurs in proportion to the traction at the anastomosis site, choosing an appropriate type of suture is important we preferred polypropylene. Suture tension should be appropriate and the suture knot should be formed outside the trachea to prevent formation of granulation tissue. Behrend and Klempnauer used three types of suture material (polypropylene, polydioxanone and polyglactin) in tracheal surgery in sheep. ${ }^{16}$ The results were similar in all three groups but it was noted that the suture material should be of high tensile strength and should not be absorbed in under six months. The authors concluded that the technical details (especially tension) are more important than the choice of suture material for postoperative results.

In case 1, the patient had previous history 4 endoscopic dilations followed by stenting and case 2 underwent dilation prior to LASER excision, both patients were not relieved of their complaints.In case 4 patient had undergone plain flexible bronchoscopy with dilation there was no evidence of recurrence post operatively. Dilation is achieved with lubricated bougies of increasing diameter applying radial pressure circumferentially to the narrowed airway. Balloon dilation is an alternative method. Flexible then rigid bronchoscope can also be 
used to perform blunt dissection and dilation of stenosed areas under direct vision.

For all dilating techniques, it is important that the path of the true airway lumen is identified. ${ }^{17}$ Preoperative imaging is useful for defining patient anatomy. With the associated risk of perforation and the high chance of recurrence of stenosis, one can see that dilation alone is very rarely a definitive therapy (especially in complex, high grade stenosis) and patients will ultimately need surgical intervention.

There is a paper published in 2014 by Ortiz et al, who treated 18 children with repeated endoscopic tracheal dilation. ${ }^{18}$ There was no recurrence of stenosis in any of the patients (median follow-up duration: 36 months, range: 5-72 months). However, this finding may not be replicable in the adults. Children have more favourable results with tracheal dilation as their inflammatory response is less pronounced and there is therefore less fibrous tissue formation, meaning they have a lower risk of restenosis. Ortiz et al applied mitomycin $\mathrm{C}$ as an antifibroblast agent to reduce the chance of recurrence. ${ }^{18}$ In case 5 Mitomycin $\mathrm{C}$ was applied post LASER excision and balloon dilation. There was no evidence of recurrence after 6 month follow up.

There is a lot of literature supporting the use of stents in treating benign and malignant laryngeal stenosis. Dass et al. ${ }^{19}$ conducted a study between the year 2000 2010, where out of 111 patients with laryngotracheal trauma, 71 underwent tracheal T-stenting for laryngotracheal stenosis. It was concluded that the ideal treatment option should be individualized based on patient characteristics. Stenting remained a relatively conservative treatment, was successful in a proportion of cases, and does not preclude the possibility of future reconstructive surgery if it fails. In case 1 our patient who subsequently underwent open resection and anastomosis of the stenotic segment had history of stenting after multiple failed dilations which provided him with little improvement. In case 2 patient who underwent laser assisted resection was discharged with a stent there was no evidence of recurrence.

Another method of treatment for postintubation laryngo-tracheal stenosis is Neodymium-doped yttrium aluminium garnet laser and cryotherapy. They have not been reported as being used in the treatment of postintubation laryngeal stenosis except in very small series or case reports with no long-term follow-up review.

In two of our cases (case 2 and 3 ), $\mathrm{CO}_{2}$ diode LASER was used for excision of the subglottic stenosis. In one of our cases (case 5) Holmium LASER was used for subglottic stenosis excision. In all the three cases of LASER there was improvement in airway and no evidence of stridor post operatively.

It is seen that open surgical procedures involved certain potential risks not associated with endoscopic techniques including increased anaesthesia time, lengthy hospitalization. Because of these reasons there has been a general tendency to treat laryngo-tracheal stenosis with endoscopic techniques. Addition of LASER has offered new dimension in improving the conventional endoscopic technique in the management of laryngotracheal stenosis. Use of LASER coupled to a rigid/flexible bronchoscope and ventilating bronchoscope allowed the surgeon to perform hands off endoscopic surgery such as scar excision or vaporization with increased precision. In our three cases treated by endoscopic laser, the patient could be decannulated after the procedure giving a fairly good success rate. Simpson et $a^{20}{ }^{20}$ successfully treated 1 of $5(20 \%)$ patients having combined laryngeal and tracheal stenosis with endoscopic laser excision. Minimal pain, low levels of intraoperative and postoperative oedema, faster healing with less scar and improved hemostasis are advantages of laser use.

There is much evidence in the literature suggesting that for the treatment of subglottic stenosis, resection by endoscopy with laser and open surgical technique end to end anastomosis are the best available modality with regard to long-term results. ${ }^{21-24}$

Our study supports this theory to perform resection for stenosis by end to end anastomosis or endoscopy with laser on patients who have had previous interventions.

\section{Conclusion}

Endotracheal intubation is lifesaving when there is a need for artificial ventilation, but it isn't without 
risk. Development of tracheal stenosis, that too of higher grade, is one of the most dreaded complication. However, such conditions can be managed with high degree of success.

Resection and primary anastomosis and LASER assisted excision of stenotic portion is a safe option for the treatment of subglottic stenosis following intubation in grade 3 or 4 stenosis without the need for repeated dilation. Collaboration is needed between thoracic and ENT surgeons to develop protocols for management of postintubation laryngo-tracheal stenosis as patients may present to both specialties.

Improved hemostasis, lesser pain, lesser postoperative oedema, faster healing with less scar are advantages of LASER, thus making it a safe option in management of tracheal stenosis.

Given the high rates of recurrence, we cannot see a role for dilation alone in centres where specialised tracheal surgeons are available. Endoscopic dilation can be reserved for unfit patients or as a measure in nonequipped centres.

\section{References}

1. Grillo HC, Donahue DM, Mathisen DJ, Wain JC, Wright CD. Postintubation tracheal stenosis. Treatment and results. J Thorac Cardiovasc Surg. 1995; 09(3):486-92

2. Anand VK, Alemar G, Warren ET. Surgical considerations in tracheal stenosis. Laryngoscope.1992; 102(3):237-43

3. Wain JC. Post intubation tracheal stenosis. Chest Surg Clin N Am. 2003; 231-46

4. Nouraei SA, Ma E, Patel A et al. Estimating the population incidence of adult post-intubation laryngotracheal stenosis. Clin Otolaryngol. 2007: 411-2

5. Zias N, Chroneou A, Tabba MK et al. Post tracheostomy and post intubation tracheal stenosis: report of 31 cases and review of the literature. BMC Pulm Med. 2008; 18.

6. Spittle N, McCluskey A. Tracheal stenosis after intubation. BMJ. 2000; 321:1000-2. doi: 10.1136/bmj.321.7267.1000

7. Dutau H. Proceedings of the 12th world congress for bronchology. Boston, Bologna: Monduzzi Editore; 2002. Tracheal stenosis endoscopic treatment; pp. 83-8.

8. Papla B, Dyduch G, Frasik W, Olechnowica H. Post-intubation tracheal stenosis- morphological-clinical investigations. Pol J Pathol. 2013; 54:261-6

9. Esteller-Moré E, Ibañez J, Matiñó E, Ademà JM, Nolla M, Quer IM. Prognostic factors in laryngotracheal injury following intubation and/or tracheotomy in ICU patients. Eur Arch Otorhinolaryngol. 2005; 262:880-3. doi: 10.1007/s00405-0050929-y

10. Endobronchial Treatment of complete tracheal stenosis Report of 3 cases and description of an innovative technique. Ann Thorac Surg. 2013; 95:3514.doi:10.1016 /j. athoracsur 201.05.061

11. Zias N, Chroneou A, Tabba MK, Gonzalez AV, Gray AW, Lamb CR, et al. Post tracheostomy and post intubation tracheal stenosis: report of 31 cases and review of the literature. BMC Pulm Med. 2008; 8:18. Doi :10.1186/1471-2466-8-18

12. Cinnamond MJ. Stridor. In: Kerr AG, Groves J, Evans JG (editors). Scott-Brown's Otolaryngology (5th ed.). London: Butterworths \& Co Ltd; 1987.p.420-7

13. Keshava K, Weingarten JA, Grosu HB. "Benign" tracheal stenosis in an 18-year-old man. Ann Am Thorac Soc. 2013; 10(6):701-3. doi: 10.1513/AnnalsATS.201306-199OT

14. Myer CM, O'Connor DM, Cotton RT. Proposed grading system for subglottic stenosis based on endotracheal tube sizes. Ann Otol Rhinol Laryngol. 1994; 319-23

15. Galluccio G, Lucantoni G, Battistoni P et al. Interventional endoscopy in the management of benign tracheal stenoses: definitive treatment at long-term follow-up. Eur J Cardiothorac Surg. 2009; 429-33

16. Behrend M, Klempnauer J. Influence of suture material and technique on end-to-end reconstruction in tracheal surgery: an experimental study in sheep. Eur Surg Res. 2001; 210-16

17. Bacon JL, Patterson CM, Madden BP. Indications and interventional options for non-resectable tracheal stenosis. J Thorac Dis. 2014;: 258-70

18. Ortiz R, Dominguez E, De La Torre C et al. Early endoscopic dilation and mitomycin application in the treatment of acquired tracheal stenosis. Eur J Pediatr Surg. 2014; 39-45

19. Arjun Dass et al. Tracheal T-Tube Stent for Laryngotracheal Stenosis: Ten Year Experience; Iran J Otorhinolaryngol. 2014; 26(74):37-42

20. Zalzal GH, Cotton RT, Mc Adams J. The survival of Costal Cartilage graft in Laryngotracheal Reconstruction. Otolaryngol Head Neck Surg. 1986; 94:204-11

21. George M, Lang F, Pasche P, Monnier P. Surgical management of laryngotracheal stenosis in adults. Eur Arch Otorhinolaryngol. 2005; 609-15

22. Marques P, Leal L, Spratley J et al. Tracheal resection with primary anastomosis: 10 years experience. Am J Otolaryngol. 2009; 415-8

23. Grillo HC, Donahue DM, Mathisen DJ et al. Postintubation tracheal stenosis. J Thorac Cardiovasc Surg.1995;109: 486-92

24. Hassan FH, Goh BS, Kong MH et al. Tracheal resection and anastomosis: an 11 year management outcome. Rawal Med J. 2013; 38: 177-80. 